\title{
Determinants of time-to-disposition in patients who underwent CT for pulmonary embolism: a retrospective study
}

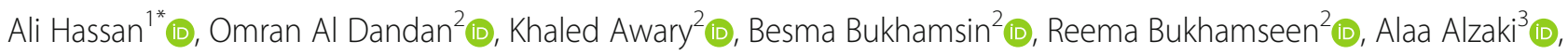
Amal Al-Sulaibeekh ${ }^{4}$ (D) and Hind S. Alsaif ${ }^{2}$ (D)

\begin{abstract}
Background: Pulmonary embolism (PE) is a common life-threatening medical emergency that needs prompt diagnosis and management. Providing urgent care is a key determinant of quality in the emergency department (ED) and time-based targets have been implemented to reduce length of stay and overcrowding. The study aimed to determine factors that are associated with having a time-to-disposition of less than $4 \mathrm{~h}$ in patients with suspected PE who underwent computed tomography pulmonary angiography (CT-PA) to confirm the diagnosis.
\end{abstract}

Methods: After obtaining approval from the ethics committee, we conducted a retrospective observational study by examining CT-PA scans that was performed to rule out PE in all adult patients presenting at the ED between January 2018 and December 2019. Demographic information and clinical information, as well as arrival and disposition times were collected from electronic health records. Multivariable regression analysis was used to identify the independent factors associated with meeting the 4-h target in the ED.

Results: In total, the study involved 232 patients (76 men and 156 women). The median length of stay in the ED was $5.2 \mathrm{~h}$ and the 4 -h target was achieved in $37 \%$ of patients. Multivariable logistic regression analysis revealed that a positive CT-PA scan for PE was independently associated with meeting the four-hour target in the ED (odds ratio [OR]: 2.2; 95\% Cl: 1.1-4.8). Furthermore, Hemoptysis was the only clinical symptom that served as an independent factor associated with meeting the 4-h target in the ED (OR: 10.4; 95\% Cl: 1.2-90.8).

Conclusion: Despite the lower number of staff and higher volume of patients on weekends, patients who presented on weekends had shorter stays and were more likely to meet the 4-h target. Careful clinical assessment, prior to requesting a CT-PA scan, is crucial, since negative CT-PA scans may be associated with failure to meet the 4-h target.

Keywords: Pulmonary embolism, Emergency department, Length of stay, 4-h target

\section{Background}

Pulmonary Embolism (PE) is a common lifethreatening medical condition that is often misdiagnosed since it lacks characteristic clinical features. Computed tomography pulmonary angiography (CT-

\footnotetext{
* Correspondence: alihy8@gmail.com

${ }^{1}$ Department of Radiology, Salmaniya Medical Complex, Manama, Bahrain Full list of author information is available at the end of the article
}

PA) has become the first-line imaging modality of choice for the diagnosis of PE because of its high accuracy and non-invasive nature. The mortality from untreated PE can reach up to $30 \%$. Notably, it is estimated that two thirds of mortalities occur within the first $2 \mathrm{~h}$ after clinical presentation [1]. Hence, timely diagnosis and management is essential due to the substantial effect on mortality and morbidity [2].

C C The Author(s). 2021 Open Access This article is licensed under a Creative Commons Attribution 4.0 International License, which permits use, sharing, adaptation, distribution and reproduction in any medium or format, as long as you give appropriate credit to the original author(s) and the source, provide a link to the Creative Commons licence, and indicate if changes were made. The images or other third party material in this article are included in the article's Creative Commons licence, unless indicated otherwise in a credit line to the material. If material is not included in the article's Creative Commons licence and your intended use is not permitted by statutory regulation or exceeds the permitted use, you will need to obtain permission directly from the copyright holder. To view a copy of this licence, visit http://creativecommons.org/licenses/by/4.0/. The Creative Commons Public Domain Dedication waiver (http://creativecommons.org/publicdomain/zero/1.0/) applies to the data made available in this article, unless otherwise stated in a credit line to the data. 
Providing urgent care is a key focus in the emergency departments (ED) as delays may lead to significant adverse outcomes [3]. Reducing the length of stay in the ED has thus attracted much attention as a key determinant of quality $[4,5]$. Overcrowding in EDs has been associated with delays in the administration of medications, admission to the wrong wards, and increased medical errors [6]. Crowding could have negative effects on healthcare providers, including increased risk of violence and decreased job satisfaction $[7,8]$.

In our institution, the 4-h target, which aims to limit the time between arrival and disposition decision to a maximum of $4 \mathrm{~h}$, was introduced in 2016 resulting in a decreased length of stay in the ED. This time-based target was first implemented by the National Health Service (NHS) in the United Kingdom in 2004 and was adopted by the Australian government in 2012 [9, 10]. However, the NHS has modified its target to $95 \%$ of patients to allow for certain clinical exceptions [11]. Several studies have demonstrated the benefits of the 4-h rule. Waiting times in the ED were significantly reduced and a reduction in mortality rates following the introduction of time-based targets has also been demonstrated [9, 12, 13].

While the use of complex imaging is often thought to be a culprit of prolonged ED stays [11], it seems unlikely to be a causative factor for breaching time-based targets. For example, a retrospective study revealed that most patients who exceeded the target had stayed over $4 \mathrm{~h}$ after the imaging itself was completed [14]. Several studies have explored the determinants of length of stay in EDs [11, 15, 16]. However, it would be of special interest to investigate the length of stays for the group of patients with suspected $\mathrm{PE}$ who underwent imaging to rule it out.

Considering the widespread availability of CT-PA, it is unsurprising to see a low threshold for its use in the diagnosis of PE [17]. It remains unclear, however, whether CT-PA results could influence the length of stay in the ED. Time-based targets could potentially compel physicians not to request a D-dimer assay prior to a CT-PA scan even if the patient is deemed unlikely to have PE [18]. No previous study has investigated the effects of skipping the D-Dimer assay and proceeding directly to a CT-PA scan on compliance with timebased targets. Furthermore, radiology report turnaround times could be higher during on-call hours where a consultant radiologist may not be immediately available [19]. This could influence compliance with time-based targets in the ED according to the shift periods.

Therefore, this study aimed to investigate the length of stay among patients who underwent CT-PA scans for suspected $\mathrm{PE}$ and to determine the patient and environmental factors that serve as independent factors associated with meeting the 4-h target in ED.

\section{Materials and methods Study design}

After obtaining approval from the ethics committee, we conducted a retrospective study to investigate the determinants of length of stay for patients who underwent CT-PA for suspected PE and the compliance with the 4$h$ target in the ED.

\section{Study setting}

The study was conducted at the King Fahd Hospital of Imam Abdulrahman Bin Faisal University, an academic center located in the Eastern Province of Saudi Arabia. Each year, approximately 250,000 patients visit the ED. CT-PA scans can only be requested by board-certified consultant physicians.

\section{Study population}

The Radiology Information System was used to identify all requests for CT-PA scans for patients presenting at the ED between January 2018 and December 2019. Eligible participants were adult patients who underwent CT-PA to rule out PE. Exclusion criteria were as follows: age below 18 years, pregnancy, and the purpose of the scan was not to rule out PE.

\section{Data collection}

A structured data collection form was created using the QuestionPro platform (Seattle, WA, USA) to collect data from patient electronic health records that included:

- Patient-Related Information: Age, sex, comorbidities, presenting sign and symptoms, D-dimer level, and CT-PA findings were obtained. The Charlson Comorbidity Index (CCI) score, an important measure of burden of disease [20], was calculated for each patient. Tachycardia was defined as heart rate > $100 \mathrm{bpm}$, hypotension was defined as blood pressure $<90 / 60 \mathrm{mmHg}$, and hypoxia was defined as an oxygen saturation $<95 \%$ on room air. The Wells score was calculated retrospectively from the data available in the electronic health record in case the score was not explicitly stated in the patient record.

- Environment-Related Information: Data on date and time of presentation and disposition were obtained. Length of stay was estimated as the difference between the time of presentation and the time of disposition (discharge, admission, or referral).

The data collection process was performed by a diagnostic radiology resident who was familiar with the Hospital Information System and received adequate training and supervision by the principal investigator. The data was checked by the principal investigator and 
inconsistent data was revised by referring to the electronic records again.

\section{Statistical analysis}

After checking for completeness and accuracy, data were analyzed using IBM SPSS for Windows, version 26 (IBM Corp., Armonk, NY, USA). Categorical variables, presented as percentages and frequency distribution, were compared using the chi-squared or Fisher's exact tests, as appropriate. Continuous variables, presented as median and interquartile range (IQR), were compared using the Mann-Whitney $U$ and Kruskal-Wallis tests, as appropriate. The Wells score was dichotomized according to the two-tier model with the "PE likely" group has a score $>4.0$ and the "PE unlikely" group has a score $\leq 4.0$. Multivariable binary logistic regression analysis was conducted to identify the independent factors associated with meeting the 4-h target in the ED. Candidate variables were selected based on risk factors identified in the literature and bivariate analyses. Odds ratio (OR) with $95 \%$ confidence interval $(\mathrm{CI})$ were estimated using the full model fit and were reported in comparison with the designated reference group. The goodness-of-fit of the model was evaluated using the Omnibus and Hosmer-Lemeshow tests. The significance level was defined as $\alpha=0.05$. The Bonferroni correction was used for multiple comparisons.

\section{Results}

Patient characteristics

The study involved 232 patients (76 men and 156 women) who presented to the ED and underwent CTPA scan to rule out PE. Only 34 (14.6\%) patients had a $\mathrm{PE}$ and a D-dimer assay was requested for 137 (59.1\%) patients. Table 1 summarizes the information pertaining

Table 1 Characteristics of clinical encounters according to patient and environmental factors

\begin{tabular}{|c|c|c|c|c|}
\hline \multicolumn{3}{|l|}{ Variables } & \multicolumn{2}{|c|}{$\mathrm{N}(\%)$} \\
\hline \multirow[t]{20}{*}{ Patient Factors } & Age $<50$ years & & 186 & $(80.2)$ \\
\hline & Male Sex & & 76 & $(32.8)$ \\
\hline & \multirow{4}{*}{$\begin{array}{l}\text { Charlson } \\
\text { Comorbidity Index }\end{array}$} & 0 & 110 & $(47.6)$ \\
\hline & & $1-2$ & 57 & (24.6) \\
\hline & & $3-4$ & 28 & $(12.1)$ \\
\hline & & $\geq 5$ & 37 & $(15.9)$ \\
\hline & \multirow[t]{7}{*}{ Clinical Symptoms } & Asymptomatic & 9 & (3.9) \\
\hline & & Dyspnea & 176 & $(75.9)$ \\
\hline & & Chest Pain & 124 & (53.4) \\
\hline & & Cough & 57 & (24.6) \\
\hline & & Hemoptysis & 7 & (3.0) \\
\hline & & Leg Pain or Swelling & 23 & (9.9) \\
\hline & & Syncope & 7 & (3.0) \\
\hline & \multirow[t]{4}{*}{ Clinical Signs } & Tachycardia & 129 & (55.6) \\
\hline & & Hypoxia & 59 & $(25.4)$ \\
\hline & & Hypotension & 6 & (2.6) \\
\hline & & Altered Consciousness & 14 & $(6.0)$ \\
\hline & \multicolumn{2}{|l|}{ Ordered D-Dimer Assay } & 95 & $(40.9)$ \\
\hline & \multicolumn{2}{|l|}{ Positive CT-PA for PE } & 34 & $(14.7)$ \\
\hline & \multicolumn{2}{|l|}{$\begin{array}{l}\text { High Probability of PE } \\
\text { based on Wells Criteria }\end{array}$} & 50 & (21.6) \\
\hline \multirow[t]{7}{*}{ Environmental Factors } & \multirow[t]{2}{*}{ Year of Presentation } & 2018 & 136 & (58.6) \\
\hline & & 2019 & 96 & (41.4) \\
\hline & \multicolumn{2}{|l|}{$\begin{array}{l}\text { Presented in October } \\
\text { (Beginning of Academic Year) }\end{array}$} & 176 & $(75.9)$ \\
\hline & \multicolumn{2}{|l|}{ Presented in Weekend } & 56 & (24.1) \\
\hline & \multirow[t]{3}{*}{ Shift Period } & Morning & 65 & $(28.0)$ \\
\hline & & Evening & 97 & $(41.8)$ \\
\hline & & Night & 70 & $(30.2)$ \\
\hline
\end{tabular}


to the clinical encounters according to patient and environmental factors.

\section{Time-to-disposition}

The median time-to-disposition from the ED was $5.2 \mathrm{~h}$ (IQR: 2.8-7.0). The time-to-disposition according to different patient and environmental factors is summarized in Table 2. On bivariate analysis, there was no significant difference in the time-to-disposition according to the patient's age, sex, CCI, or presenting symptoms. However, the time-to-disposition was significantly lower in patients who presented with hypoxia $(4.2 \mathrm{~h}$ vs. $5.3 \mathrm{~h} ; U=$ 4171.0, $P=0.04)$ and altered level of consciousness $(3.1 \mathrm{~h}$ vs. $5.3 \mathrm{~h} ; U=887.5, P=0.01$ ). The time-to-disposition of patients who had a D-dimer assay was longer than that of patients who did not have the assay (5.3 h vs. $4.9 \mathrm{~h}$ ), although the difference was not statistically significant $(U=6110.5, P=0.43)$. The patients who were found to have a PE in the CT-PA had a significantly shorter length of stay ( $3.7 \mathrm{~h}$ vs. $5.3 \mathrm{~h} ; U=2497.5, P=0.02$ ).

Table 2 Time-to-disposition according to different patient and environmental factors

\begin{tabular}{|c|c|c|c|c|c|c|}
\hline Variables & & & $\begin{array}{l}\text { Median Time to } \\
\text { Disposition (Hours) }\end{array}$ & $P$ value $^{a}$ & $\begin{array}{l}\text { Meeting the } \\
\text { Four-Hour Target (\%) }\end{array}$ & $P$ value ${ }^{a}$ \\
\hline \multirow[t]{23}{*}{ Patient Factors } & \multirow[t]{2}{*}{ Age } & $<50$ years & 5.2 & 0.87 & 37 & 0.75 \\
\hline & & $\geq 50$ years & 5.4 & & 39 & \\
\hline & \multirow[t]{2}{*}{ Gender } & Male & 4.5 & 0.09 & 45 & 0.09 \\
\hline & & Female & 5.4 & & 33 & \\
\hline & \multirow{4}{*}{$\begin{array}{l}\text { Charlson Comorbidity } \\
\text { Index }\end{array}$} & 0 & 4.8 & 0.32 & 40 & 1.00 \\
\hline & & $1-2$ & 5.4 & & 35 & \\
\hline & & $3-4$ & 6.2 & & 21 & \\
\hline & & $\geq 5$ & 4.5 & & 43 & \\
\hline & \multirow[t]{7}{*}{ Clinical Symptoms } & Asymptomatic & 6.8 & 0.34 & 22 & 0.35 \\
\hline & & Dyspnea & 5.0 & 0.29 & 39 & 0.23 \\
\hline & & Chest Pain & 5.0 & 0.45 & 40 & 0.41 \\
\hline & & Cough & 5.2 & 0.46 & 37 & 0.97 \\
\hline & & Hemoptysis & 3.1 & 0.11 & 86 & 0.01 \\
\hline & & Leg Pain or Swelling & 4.7 & 0.38 & 48 & 0.26 \\
\hline & & Syncope & 5.6 & 0.82 & 29 & 0.64 \\
\hline & \multirow[t]{4}{*}{ Clinical Signs } & Tachycardia & 4.9 & 0.69 & 39 & 0.55 \\
\hline & & Hypoxia & 4.2 & 0.04 & 46 & 0.11 \\
\hline & & Hypotension & 4.4 & 0.34 & 17 & 0.29 \\
\hline & & Altered Consciousness & 3.1 & 0.01 & 64 & 0.03 \\
\hline & \multirow[t]{2}{*}{ D-Dimer Assay } & Ordered & 5.3 & 0.43 & 34 & 0.37 \\
\hline & & Not Ordered & 4.9 & & 39 & \\
\hline & \multirow[t]{2}{*}{ CT-PA Report } & Positive for PE & 3.8 & 0.02 & 53 & 0.04 \\
\hline & & Negative for PE & 5.3 & & 34 & \\
\hline \multirow{9}{*}{$\begin{array}{l}\text { Environmental } \\
\text { Factors }\end{array}$} & \multirow[t]{2}{*}{ Year of Presentation } & 2018 & 5.3 & 0.86 & 38 & 0.87 \\
\hline & & 2019 & 5.2 & & 36 & \\
\hline & \multirow[t]{2}{*}{ Month of Presentation } & $\begin{array}{l}\text { October } \\
\text { (Beginning of Academic Year) }\end{array}$ & 5.5 & 0.88 & 37 & 0.62 \\
\hline & & Other Months & 5.2 & & 44 & \\
\hline & \multirow[t]{2}{*}{ Day of Presentation } & Weekday & 5.6 & 0.01 & 34 & 0.047 \\
\hline & & Weekend & 4.1 & & 48 & \\
\hline & \multirow[t]{3}{*}{ Shift Period } & Morning & 4.6 & 1.00 & 42 & 1.00 \\
\hline & & Evening & 5.2 & & 37 & \\
\hline & & Night & 5.5 & & 33 & \\
\hline
\end{tabular}


There was a significant difference in the time-todisposition in patients according to the day of presentation. Patients who presented over the weekend had a shorter length of stay by approximately half an hour when compared with patients presenting on weekdays ( $4.1 \mathrm{~h}$ vs. $5.6 \mathrm{~h} ; U=3845.5, P=0.01$ ). However, there was no significant difference according to the year or month of presentation or the shift period $(P>0.05)$.

\section{Compliance with the 4-hour target}

The 4-h target was achieved in $37 \%$ of patients. As shown in Table 2, the compliance rate did not significantly differ according to patient demographic factors. Overall, $86 \%$ of patients presenting with hemoptysis stayed in the ED for less than $4 \mathrm{~h}$ compared to $36 \%$ of patients who did not present with hemoptysis $\left(x^{2}=\right.$ 7.322, $P=0.01$ ). Similarly, $64 \%$ of patients presenting with altered consciousness met the 4-h target compared to $35 \%$ of patients with a normal level of consciousness $\left(\chi^{2}=4.731, P=0.03\right)$.

\section{Multivariable analysis of factors associated with meeting the 4-hour target}

Multivariable binary logistic regression analysis was conducted to identify patient and environmental factors that are associated with meeting the 4-h target in the ED after controlling for the likelihood of PE based on the Wells criteria. A test of the full model vs. the interceptonly model was statistically significant $\left(\chi^{2}=21.1, P=\right.$ 0.004).

The model revealed that the CT-PA result was an independent factor associated with meeting the 4-h target, as patients who were found to have PE had a higher tendency of staying less than 4-h in the ED (OR: 2.2; 95\% CI: 1.1-4.8). Hemoptysis was the only clinical symptom that served as an independent factor associated with meeting the 4-h target in the ED (OR: 10.4; 95\% CI: 1.290.8) (Table 3).

\section{Discussion}

Our study aimed to investigate the factors that determined the length of stay and compliance with the 4-h target in the ED for patients who underwent CT-PA to rule out PE. We found that a positive CT-PA for PE and hemoptysis were independent factors associated with meeting the 4-h target in the ED.

A positive CT-PA scan was found to be associated with a shorter length of stay in the ED, suggesting that unjustified CT-PA scans may delay disposition and discharge of patients with suspected PE. This finding may suggest that having a clear diagnosis could make disposition easier and faster. While there is no clinical protocol in place for PE, it is the usual practice in our institution to refer patients with confirmed PE to the hematology team for further management. Several studies have demonstrated the value of having clear clinical protocols in the ED for the patient care, including reducing length of stays [21, 22]. Furthermore, incidental findings in CTPA scans are common [23], and previous studies have demonstrated that incidental radiological findings were associated with longer stays [24, 25].

Although there is no accurate data about variation in the use of EDs according to day of the week, anecdotal information suggests that use is higher on the weekends. Moreover, a retrospective study conducted in the United States showed that EDs were visited more often on weekends [26]. It was demonstrated in previous research that the root causes of longer stays in the ED were mostly organizational in nature and beyond the control of the ED [27].

Counterintuitively, the study found that these weekend ED visits had shorter stays and higher compliance with the 4-h rule. A retrospective single-institution study involving more than 300,000 ED visits had a similar pattern revealing that the highest use of the $\mathrm{ED}$ on weekends, but the highest probability of breaching the time-based targets was on days following weekends [11]. This interesting finding was attributed to the high number of admissions on weekends resulting in a shortage of

Table 3 Multivariable logistic regression of factors associated with meeting the four-hour target

\begin{tabular}{|c|c|c|c|c|c|c|}
\hline \multirow[t]{2}{*}{ Variables } & \multicolumn{3}{|c|}{ Univariable Logistic Regression } & \multicolumn{3}{|c|}{ Multivariable Logistic Regression } \\
\hline & $\overline{\mathrm{OR}}$ & {$[95 \% \mathrm{Cl}]$} & $P$ value ${ }^{a}$ & $\overline{\mathrm{OR}}$ & {$[95 \% \mathrm{Cl}]$} & $P$ value ${ }^{a}$ \\
\hline Age $\geq 50$ years & 0.9 & {$[0.5,1.7]$} & 0.75 & 1.0 & {$[0.5,2.1]$} & 0.95 \\
\hline Male patient & 0.6 & {$[0.4,1.1]$} & 0.09 & 1.4 & {$[0.8,2.5]$} & 0.29 \\
\hline Hemoptysis & 10.9 & {$[1.3,91.9]$} & 0.03 & 10.4 & {$[1.2,90.8]$} & 0.03 \\
\hline Altered consciousness & 3.3 & {$[1.1,10.2]$} & 0.04 & 3.0 & {$[0.9,10.0]$} & 0.08 \\
\hline CT-PA was positive for PE & 2.2 & {$[1.03,4.5]$} & 0.04 & 2.2 & {$[1.1,4.8]$} & 0.02 \\
\hline Weekend presentation & 1.8 & {$[1.0,3.4]$} & 0.049 & 2.0 & {$[0.9,3.3]$} & 0.10 \\
\hline "PE likely" Wells score & 1.6 & {$[0.9,3.0]$} & 0.14 & 1.2 & {$[0.6,2.4]$} & 0.57 \\
\hline
\end{tabular}

Abbreviation: $\mathrm{Cl}$ Confidence interval, CT-PA Computed tomography pulmonary angiography, OR Odds ratio, PE Pulmonary embolism

${ }^{a} P$ value in bold when significant 
inpatient beds on the weekdays and delays in admitting the patients to inpatient beds $[11,28]$. While this explanation is reasonable, we also assume that because outpatient clinics are not available on the weekends, the turnaround time for radiological and laboratory tests for patients presenting at the ED could be shorter, which facilitating the diagnosis and disposition of patients on weekends. However, the multivariable model did not show a significant difference in achieving the 4-h target based on the day of presentation to the ED. It is worthmentioning that there was not a significant difference in length of stay or compliance with the 4-h target in October, which is the beginning of the academic year in our institution, compared to other months.

Radiology departments may be affected by time-based targets in ED. A retrospective study by Tse et al. [14] to assess trends in requests for radiology, before and after introduction of a 4-h standard, showed an increase of $60 \%$ after introduction of the rule. The study also revealed a shift toward the use of more CT scans compared with plain X-ray images [14]. Current guidelines for the management of $\mathrm{PE}$ recommend using the Ddimer assay in patients with a low pre-test probability of $\mathrm{PE}$ [29]. A recent study from our institution revealed that one-third of all CT-PA scans requested by physicians in the ED did not adhere to clinical decision rules and that the D-dimer assay was significantly underused. Therefore, it has been suggested that time targets in EDs may compel physicians to request a CT-PA scan without having a D-dimer assay, even if the patient is deemed unlikely to have PE [30]. While the present study found that there was a notable difference of approximately half an hour in the length of stay between patients who had D-dimer assay and those who did not, it should be noted that our study included the patients who underwent a CT-PA scan only. The predictive value of normal Ddimer levels for exclusion of PE was over 99\% and clinical probability, combined with a D-dimer assay, may thus exclude the need for further investigations and could reduce the length of stay significantly [31]. In the appropriate setting, ED physicians should, therefore, not be reluctant to request a D-dimer assay just for the sake of meeting time-based targets.

Our study had certain limitations. It represented a single-center experience and included all patients with suspected PE who presented at the ED over 2 years. We also did not collect detailed descriptions of events during the ED stay, such as time from image request to discharge, which could have given a better understanding of contributions to length of stay.

\section{Conclusion}

The meeting of the 4-h target was not significantly associated with most of the patient and environmental factors. Careful clinical assessment, prior to requesting a CT-PA scan, is crucial, because negative CT-PA scans may be associated with failure to meet the 4-h target. The findings of this study may enable stakeholders to implement appropriate interventional measures to reduce the probability of exceeding the 4-h target.

\section{Abbreviations \\ Cl: Confidence interval; CCI: Charlson comorbidity index; CT-PA: Computed tomography pulmonary angiography; ED: Emergency department; OR: Odds ratio; PE: Pulmonary embolism}

\section{Acknowledgements}

Not applicable.

\section{Authors' contributions}

Conceptualization: AH; Data collection: KA and HA; Data analysis: $\mathrm{AH}$; Methodology: AH; Writing-original draft: $A H$; Writing-review \& editing: $B B, R B$, $A A$, and AS; Supervision: OA. All authors read and approved the final manuscript.

\section{Funding}

This research received no specific grant from any funding agency in the public, commercial, or not-for-profit sectors.

\section{Availability of data and materials}

The datasets used and/or analyzed during the current study are available from the corresponding author on reasonable request.

\section{Declarations}

Ethics approval and consent to participate

The study was approved by the Institutional Review Board at the Imam Abdulrahman bin Faisal University (IAU IRB No. 2020-01-138). The need for informed consent was waived because of the retrospective nature of the study. All collected data were de-identified and stored electronically. Only the principal investigator has access to view the stored data.

\section{Consent for publication}

Not applicable.

\section{Competing interests}

The authors declare that they have no competing interests.

\section{Author details}

${ }^{1}$ Department of Radiology, Salmaniya Medical Complex, Manama, Bahrain. ${ }^{2}$ Department of Radiology, King Fahd Hospital of the University, Imam Abdulrahman Bin Faisal University, Al-Khobar, Saudi Arabia. ${ }^{3}$ Department of Internal Medicine, King Fahd Hospital of the University, Imam Abdulrahman Bin Faisal University, Al-Khobar, Saudi Arabia. ${ }^{4}$ Department of Emergency Medicine, King Fahd Hospital of the University, Imam Abdulrahman Bin Faisal University, Al-Khobar, Saudi Arabia.

Received: 9 November 2020 Accepted: 28 September 2021 Published online: 12 October 2021

\section{References}

1. Bĕlohlávek J, Dytrych V, Linhart A. Pulmonary embolism, part I: epidemiology, risk factors and risk stratification, pathophysiology, clinical presentation, diagnosis and nonthrombotic pulmonary embolism. Exp Clin Cardiol. 2013;18(2):129-38.

2. Goldhaber SZ, Visani L, De Rosa M. Acute pulmonary embolism: clinical outcomes in the international cooperative pulmonary embolism registry (ICOPER). Lancet. 1999;353(9162):1386-9. https://doi.org/10.1016/S0140-673 6(98)07534-5.

3. Guttmann A, Schull MJ, Vermeulen MJ, Stukel TA. Association between waiting times and short term mortality and hospital admission after departure from emergency department: population based cohort study from Ontario, Canada. BMJ. 2011;342(jun01 1):d2983. https://doi.org/10.113 6/bmj.d2983. 
4. Bernstein SL, Aronsky D, Duseja R, Epstein S, Handel D, Hwang U, et al. The effect of emergency department crowding on clinically oriented outcomes. Acad Emerg Med. 2009;16(1):1-10. https://doi.org/10.1111/j.1553-2712.2008.00295.x.

5. Richardson DB. Increase in patient mortality at 10 days associated with emergency department overcrowding. Med J Aust. 2006;184(5):213-6. https://doi.org/10.5694/j.1326-5377.2006.tb00204.x.

6. Morris ZS, Boyle A, Beniuk K, Robinson S. Emergency department crowding: towards an agenda for evidence-based intervention. Emerg Med J. 2012; 29(6):460-6. https://doi.org/10.1136/emj.2010.107078.

7. Popa F, Arafat R, Purcarea VL, Lala A, Popa-Velea O, Bobirnac G. Occupational burnout levels in emergency medicine--a stage 2 nationwide study and analysis. J Med Life. 2010;3(4):449-53.

8. Stirling G, Higgins JE, Cooke MW. Violence in A\&E departments: a systematic review of the literature. Accid Emerg Nurs. 2001;9(2):77-85. https://doi.org/1 0.1054/aaen.2000.0204.

9. Sullivan C, Staib A, Khanna S, Good NM, Boyle J, Cattell R, et al. The National Emergency Access Target (NEAT) and the 4-hour rule: time to review the target. Med J Aust. 2016;204(9):354. https://doi.org/10.5694/mja15.01177.

10. Eatock J, Cooke M, Young TP. Performing or not performing: what's in a target? Future Healthc J. 2017;4(3):167-72. https://doi.org/10.7861/ futurehosp.4-3-167.

11. Bobrovitz N, Lasserson DS, Briggs ADM. Who breaches the four-hour emergency department wait time target? A retrospective analysis of 374,000 emergency department attendances between 2008 and 2013 at a type 1 emergency department in England. BMC Emerg Med. 2017;17(1):32. https:// doi.org/10.1186/s12873-017-0145-2.

12. Campbell P, Boyle A, Higginson I. Should we scrap the target of a maximum four hour wait in emergency departments? BMJ. 2017;359:44857. https://doi.org/10.1136/bmj.j4857.

13. Staib A, Sullivan C, Griffin B, Bell A, Scott I. Report on the 4-h rule and National Emergency Access Target (NEAT) in Australia: time to review. Aust Health Rev. 2016:40(3):319-23. https://doi.org/10.1071/AH15071.

14. Tse R, Thompson N, Moscova M, Sindhusake D, Shetty A, Young N. Do delays in radiology lead to breaches in the 4-hour rule? Clin Radiol. 2016; 71(6):523-31. https://doi.org/10.1016/j.crad.2016.02.008.

15. Vegting IL, Alam N, Ghanes K, Jouini O, Mulder F, Vreeburg M, et al. What are we waiting for? Factors influencing completion times in an academic and peripheral emergency department. Neth J Med. 2015:73(7):331-40.

16. Greaves F, Pappas Y, Bardsley M, Harris M, Curry N, Holder H, et al. Evaluation of complex integrated care programmes: the approach in north West London. Int J Integr Care. 2013;13(1):e006. https:/doi.org/10.5334/ijic.974.

17. Dhakal P, Iftikhar MH, Wang L, Atti V, Panthi S, Ling X, et al. Overutilisation of imaging studies for diagnosis of pulmonary embolism: are we following the guidelines? Postgrad Med J. 2019;95(1126):420-4. https://doi.org/10.113 6/postgradmedj-2018-135995.

18. Alsaif HS, Hassan A, AlSheikh M, Al-Sulaibeekh A, Alnasr A, Alzaki A, et al. Predictors of positive computed tomography pulmonary angiography results. Emerg Radiol. 2020;27(5):503-11. https://doi.org/10.1007/s10140-020-01793-2.

19. Lamb L, Kashani P, Ryan J, Hebert G, Sheikh A, Thornhill R, et al. Impact of an in-house emergency radiologist on report turnaround time. CJEM. 2015; 17(1):21-6. https://doi.org/10.2310/8000.2013.131235.

20. Charlson ME, Pompei P, Ales KL, Mackenzie CR. A new method of classifying prognostic comorbidity in longitudinal studies: development and validation. J Chronic Dis. 1987;40(5):373-83. https://doi.org/10.1016/0021-9681(87)90171-8.

21. Cadilhac DA, Dewey HM, Denisenko S, Bladin CF, Meretoja A. Changes in acute hospital costs after employing clinical facilitators to improve stroke care in Victoria, Australia. BMC Health Serv Res. 2019:19(1):41. https://doi. org/10.1186/s12913-018-3836-9

22. Rotter T, Kinsman L, James E, Machotta A, Willis J, Snow P, et al. The effects of clinical pathways on professional practice, patient outcomes, length of stay, and hospital costs: Cochrane systematic review and meta-analysis. Eval Health Prof. 2012;35(1):3-27. https://doi.org/10.1177/0163278711407313.

23. Anjum O, Bleeker H, Ohle R. Computed tomography for suspected pulmonary embolism results in a large number of non-significant incidental findings and follow-up investigations. Emerg Radiol. 2019;26(1):29-35. https://doi.org/10.1007/s10140-018-1641-8.

24. Andrawes P, Picon Al, Shariff MA, Azab B, von Waagner W, Demissie S, et al. CT scan incidental findings in trauma patients: does it impact hospital length of stay? Trauma Surg Acute Care Open. 2017;2(1):e000101. https:// doi.org/10.1136/tsaco-2017-000101.
25. Gundareddy VP, Maruthur NM, Chibungu A, Bollampally P, Landis R, Eid SM. Association between radiologic incidental findings and resource utilization in patients admitted with chest pain in an urban medical center. J Hosp Med. 2017;12(5):323-8. https://doi.org/10.12788/jhm.2722

26. Schoenfeld EM, McKay MP. Weekend emergency department visits in Nebraska: higher utilization, lower acuity. J Emerg Med. 2010;38(4):542-5. https://doi.org/10.1016/j.jemermed.2008.09.036.

27. Driesen $B E$, Van Riet BH, Verkerk L, Bonjer HJ, Merten H, Nanayakkara PW. Long length of stay at the emergency department is mostly caused by organisational factors outside the influence of the emergency department: a root cause analysis. PLoS One. 2018;13(9):e0202751. https://doi.org/10.13 71/journal.pone.0202751.

28. Lasserson DS, Chandratheva A, Giles MF, Mant D, Rothwell PM. Influence of general practice opening hours on delay in seeking medical attention after transient ischaemic attack (TIA) and minor stroke: prospective population based study. BMJ. 2008;337(sep18 3):a1569. https:/doi.org/10.1136/bmj.a1569.

29. Konstantinides SV, Meyer G, Becattini C, Bueno H, Geersing GJ, Harjola VP, et al. 2019 ESC guidelines for the diagnosis and management of acute pulmonary embolism developed in collaboration with the European Respiratory Society (ERS). Eur Heart J. 2020;41(4):543-603. https://doi.org/1 0.1093/eurheartj/ehz405.

30. Al Dandan O, Hassan A, Alnasr A, Al Gadeeb M, AbuAlola H, Alshahwan S, et al. The use of clinical decision rules for pulmonary embolism in the emergency department: a retrospective study. Int J Emerg Med. 2020;13(1): 23. https://doi.org/10.1186/s12245-020-00281-1.

31. Sharif S, Eventov M, Kearon C, Parpia S, Li M, Jiang R, et al. Comparison of the age-adjusted and clinical probability-adjusted D-dimer to exclude pulmonary embolism in the ED. Am J Emerg Med. 2019;37(5):845-50. https://doi.org/10.1016/j.ajem.2018.07.053.

\section{Publisher's Note}

Springer Nature remains neutral with regard to jurisdictional claims in published maps and institutional affiliations.

Ready to submit your research? Choose BMC and benefit from:

- fast, convenient online submission

- thorough peer review by experienced researchers in your field

- rapid publication on acceptance

- support for research data, including large and complex data types

- gold Open Access which fosters wider collaboration and increased citations

- maximum visibility for your research: over $100 \mathrm{M}$ website views per year

At $\mathrm{BMC}$, research is always in progress.

Learn more biomedcentral.com/submissions 